\title{
TEM and XPS studies to reveal the presence of cobalt and palladium particles in the inner core of carbon nanofibers
}

\author{
Ferry Winter, G. Leendert Bezemer, Cor van der Spek, Johannes D. Meeldijk, \\ A. Jos van Dillen, John W. Geus, Krijn P. de Jong * \\ Department of Inorganic Chemistry and Catalysis, Debye Institute, Utrecht University P.O. Box 80 083, 3508 TB Utrecht, The Netherlands
}

Received 7 May 2004; accepted 21 September 2004

\begin{abstract}
In this paper, the presence of a considerable number of $\mathrm{Co}(3-4 \mathrm{~nm})$ and $\mathrm{Pd}(1-4 \mathrm{~nm})$ particles in the inner tube (4-9nm inner diameter) of carbon nanofibers is demonstrated with TEM and XPS. Oxidation of freshly grown fibers in nitric acid resulted in opening of the inner tube of the fibers and in creating adsorption sites on the internal and external surface of the fibers needed for anchoring of the metal precursors. It is demonstrated that analysis with TEM tilt series is a very powerful tool to locate the actual position of the metal particles, i.e. on the external or internal surface of the fibers. The fraction of metal present in the inner core of the fibers varied from $10-15 \%$ for Pd to $28-34 \%$ for $\mathrm{Co}$, depending on the synthesis method.
\end{abstract}

(c) 2004 Elsevier Ltd. All rights reserved.

Keywords: A. Carbon fibers; B. Catalyst, Oxidation; C. Transmission electron microscopy

\section{Introduction}

Carbon nanofibers (CNF) and carbon nanotubes (CNT) receive growing attention as support material for heterogeneous catalysts because of their purity, high mechanical strength, tunable surface properties, high surface area and accessibility and the absence of micropores [1,2]. The fibers consist of stacks of graphene sheets and depending on the growth conditions and/or the type of metal used as growth catalyst, different structures can be obtained [3].

CNT, built up of coaxial cylindrical sheets, have a straight hollow core throughout the entire length of the fiber, which can easily be opened by careful oxidation in air [4] or carbon dioxide [5], or by treatment in nitric acid [6]. The diameter of the inner tubes of CNT is variable in the range of a few nanometers up to

\footnotetext{
* Corresponding author. Tel.: +31 30 2536762; fax: +31 302511027.
}

$100 \mathrm{~nm}$. With the fishbone-type CNF the graphitic layers are cone shaped and stacked on top of each other. The macroscopic CNF bodies consist of skeins of interwoven fibers $[1,3,7]$. The core of the individual fibers most probably consist of highly disordered graphene sheets or an amorphous carbon phase which is removed upon $\mathrm{HNO}_{3}$ treatment [1,8]. Only recently, it has been shown that it is also possible to grow in a single-step fishbonetype CNF with a hollow core throughout the length of the fiber [9-11]. In general, we can differentiate into three types of CNT/CNF (Fig. 1), wherein the main difference between CNF of type 1 and type 2 is the absence or presence, respectively, of a hollow core throughout the length of the fiber.

The deposition of metals and metal oxides inside CNT pre-treated as indicated has been reported by several authors [12-16]. After removing the caps of the tubes, it appeared to be possible to fill them with the metal(oxide) precursor solution.

The preparation of noble metal supported on $\mathrm{CNF} /$ CNT catalysts via impregnation and ion adsorption 

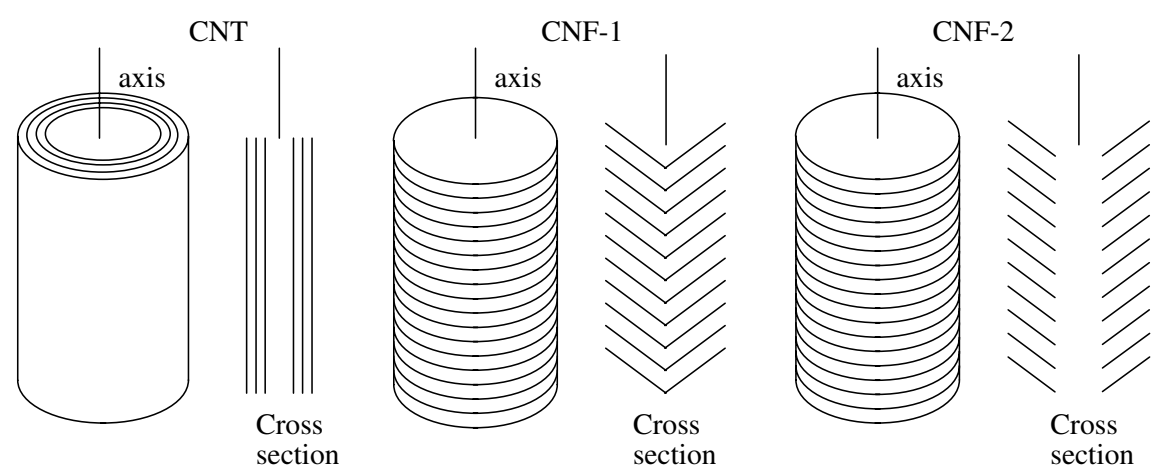

Fig. 1. Schematic representation of CNT and CNF of different types.

has been studied extensively e.g. [3,7,17-26]. In this paper we report on the application of $\mathrm{Co}$ and $\mathrm{Pd}$ by wet-impregnation/ion-adsorption techniques on $\mathrm{CNF}$, pre-treated in concentrated nitric acid. This pre-treatment is necessary to introduce adsorption sites for the polar catalyst precursor on the originally hydrophobic surface of the fibers. It also makes the inner tube accessible. To our best knowledge we are the first to establish unambiguously the presence of a considerable fraction of metal particles at the internal surface of fishbone-type fibers in the ultimate catalyst. It is demonstrated that TEM imaging of samples tilted over a sequence of angles with respect to the electron beam is a powerful tool to discriminate between particles at the external and internal fiber surface.

\section{Experimental session}

\subsection{Synthesis of carbon nanofibers}

$\mathrm{CNF}$ were grown out of synthesis gas $\left(\mathrm{H}_{2} / \mathrm{CO}\right)$ using either a commercial $57 \mathrm{wt} \% \mathrm{Ni} / \mathrm{SiO}_{2}$ catalyst (Engelhard $\mathrm{Ni} 5270 \mathrm{P}$ ) or a $20 \mathrm{wt} \% \mathrm{Ni} / \mathrm{SiO}_{2}$ catalyst, prepared as described elsewhere [1,20,27-29] at a growth temperature of $773 \mathrm{~K}$ and $823 \mathrm{~K}$, respectively. After growth, the reactor content (further denoted as CNF a.s.) was refluxed for $1.5 \mathrm{~h}$ in a $1 \mathrm{M} \mathrm{KOH}$ solution, for removal of the silica support, and after thoroughly washing treated in boiling concentrated nitric acid for $2 \mathrm{~h}$.

\subsection{Preparation of palladium and cobalt on carbon nanofibers}

The Pd/CNF ( $1 \mathrm{wt} \% \mathrm{Pd}$ ) catalyst was obtained by ion adsorption with $\mathrm{Pd}\left(\mathrm{NH}_{3}\right)_{4}^{2+}$ as described elsewhere $[3,30]$. The catalyst precursor was reduced at $523 \mathrm{~K}$ in $\mathrm{H}_{2}$ flow. $\mathrm{Co} / \mathrm{CNF}(5 \mathrm{wt} \% \mathrm{Co})$ was prepared using a wet-impregnation method as described previously [31]. The catalyst precursor was reduced in a $\mathrm{H}_{2}$ flow at $573 \mathrm{~K}$.

\subsection{Characterization}

TEM images were obtained with a Fei Technai 20 FEG TEM operating at $200 \mathrm{kV}$. Samples were, after ultrasonic treatment in butanol, dispersed on a holey carbon film. From a representative fiber a tilt series was taken from about $-60^{\circ}$ to $+45^{\circ}$ with $15^{\circ}$ intervals. The tilt axis was chosen parallel to the length of the fiber. $\mathrm{N}_{2}$ physisorption measurements were performed using a Micromeritics ASAP 2400 analyzer. Before characterization measurements were performed, the samples were out gassed in vacuum at $393 \mathrm{~K}$. Powder X-ray diffraction (XRD) was performed using an Enraf-Nonius CPS 120 powder diffraction apparatus with $\mathrm{CoK} \alpha$ radiation $(\lambda=1.789 \AA)$. X-ray Photoelectron Spectroscopy (XPS) measurements were performed on a Thermo VG Scientific XPS system using non-monochromatic $\mathrm{MgK} \alpha$ radiation. The pass energy of the analyzer was set at $70 \mathrm{eV}$. Calculations to determine the percentage of metal situated on the inner surface of CNF were performed with XPSCAT [32], a dispersion analysis program based on the original idea by Kuipers et al. [33,34]. In this model, and based on the TEM images Pd particles were assumed to have hemispherical shapes, whereas for Co particles spherical particles were used. Surface areas as determined with $\mathrm{N}_{2}$ physisorption were used in the calculations.

\section{Results and discussion}

CNF have a length of several hundreds of nanometers and diameters of around $30 \mathrm{~nm}$ for $\mathrm{Co} / \mathrm{CNF}$ (not shown) and of 20-80 nm for $\mathrm{Pd} / \mathrm{CNF}$ (Fig. 2). It appears that most of the fibers over the whole length contain an inner core present of the fiber with diameters ranging from 4 to $9 \mathrm{~nm}$. This variation is dependent on the diameter of the fiber itself. High resolution TEM (Fig. 3) shows that the fibers are indeed of the fishbone type, however, with irregularities in the graphene sheets. The distance between the graphene sheets is about 

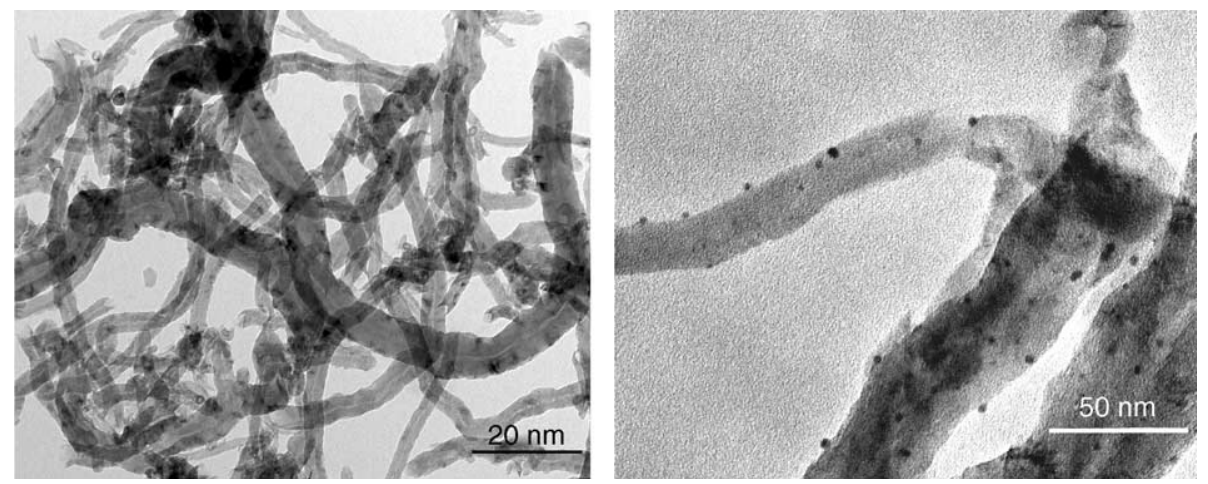

Fig. 2. Low and high magnification TEM images of Pd/CNF.

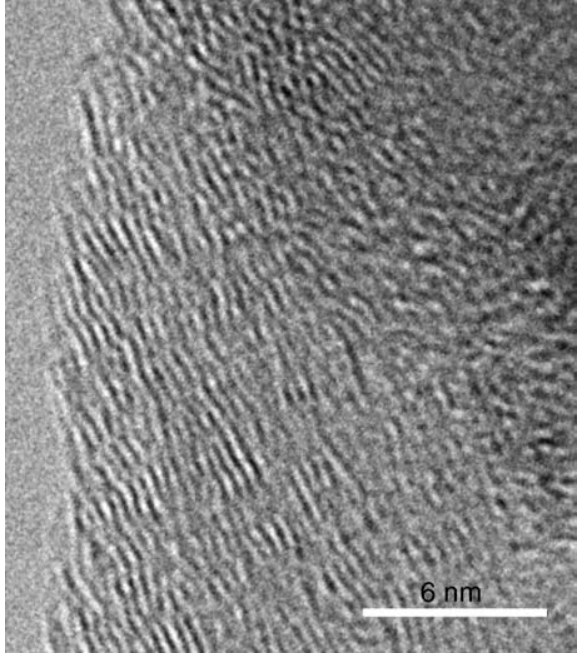

Fig. 3. High magnification TEM image of CNF.

3.4 $\AA$, a value which corresponds well with values that were obtained with XRD and to that reported by other authors $[3,8,35]$. The core in CNF a.s. is either empty, or filled by an amorphous carbon phase or highly disordered graphene sheets.

Nitrogen physisorption was performed on the CNF materials in the different synthesis stages. In Fig. 4 subsequent the adsorption and desorption isotherms of $\mathrm{CNF}$ after $\mathrm{KOH}$ treatment and after treatment in nitric acid are depicted. BET surface area and pore volume of the CNF materials are summarized in Table 1. The isotherms are characteristic for multilayer adsorption/ desorption and capillary condensation in mesopores, which causes the hysteresis loop. From the shape of the hysteresis loops the presence of cylindrical mesopores with open ends at both sides can be derived. The micropore volume, calculated with the $t$-method is very low in all samples, below $0.004 \mathrm{mlg}^{-1}$. CNF after $\mathrm{KOH}$ treatment exhibits after correction for the silica support a BET surface area similar to CNF a.s., i.e. $106 \mathrm{~m}^{2} \mathrm{~g}^{-1}$. Treatment in nitric acid increases the specific surface considerably, which demonstrates the influence of the

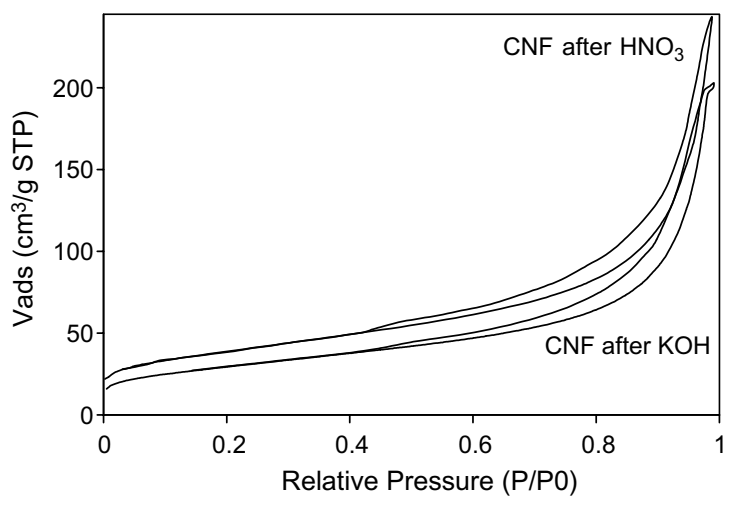

Fig. 4. Nitrogen adsorption and desorption isotherms of CNF after $\mathrm{KOH}$ and $\mathrm{CNF}$ after treatment in nitric acid.

Table 1

$\mathrm{N}_{2}$ physisorption on the CNF materials during different stages of preparation

\begin{tabular}{llll}
\hline Samples & $\begin{array}{l}\text { BET surface } \\
\text { area }\left(\mathrm{m}^{2} \mathrm{~g}^{-1}\right)\end{array}$ & $\begin{array}{l}\text { Total pore } \\
\text { volume }\left(\mathrm{mlg}^{-1}\right)\end{array}$ & $\begin{array}{l}\text { Micropore } \\
\text { volume }\left(\mathrm{mlg}^{-1}\right)\end{array}$ \\
\hline CNF a.s. & $113^{\mathrm{a}}$ & 0.32 & 0.002 \\
CNF after $\mathrm{KOH}$ & 106 & 0.26 & 0.003 \\
CNF after $\mathrm{HNO}_{3}$ & 137 & 0.38 & 0.004 \\
Pd/CNF & 138 & 0.40 & 0.003 \\
\hline
\end{tabular}

${ }^{\text {a }}$ BET surface area after correction for the $\mathrm{Ni} / \mathrm{SiO}_{2}$ growth catalyst is $107 \mathrm{~m}^{2} \mathrm{~g}^{-1}$.

oxidation step, mainly due to the opening of the inner tubes, as was earlier suggested by Toebes et al. [36].

After applying the metal on the fibers, metal particles of $1-4 \mathrm{~nm}$ for $\mathrm{Pd} / \mathrm{CNF}$ (Figs. 2 and 5) and $3-4 \mathrm{~nm}$ for $\mathrm{Co} / \mathrm{CNF}$ (Fig. 6) were found by TEM, imaged by small black dots. These particles are randomly distributed as well as ordered to a great extent over the cores of the fibers. It is emphasized that TEM gives a two-dimensional projection, which makes a decision regarding the actual location of the metal particles, i.e. inside the core or at the external surface, difficult. Recently, electron tomography has been used to analyze porous catalysts [37-39]. TEM images taken over an angular tilt 


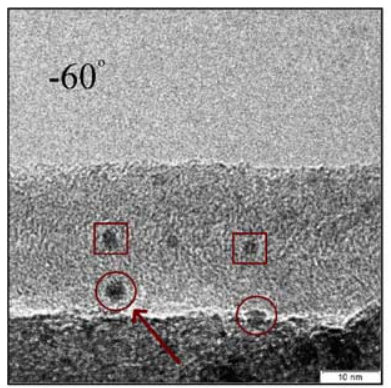

(a)

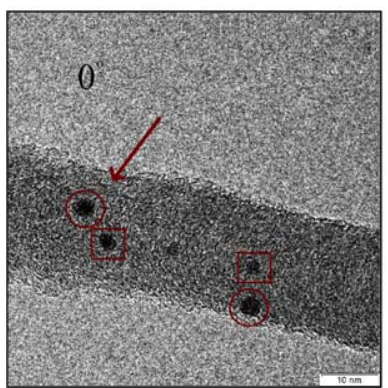

(e)

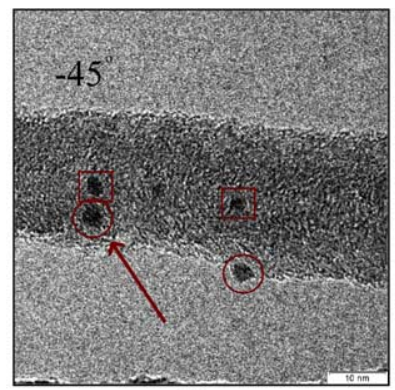

(b)

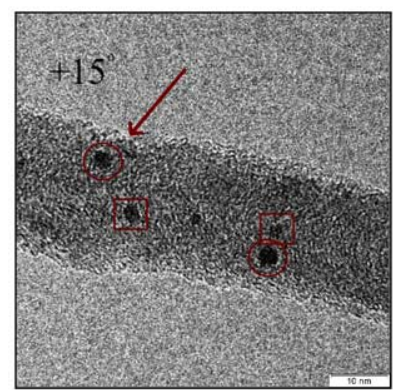

(f)

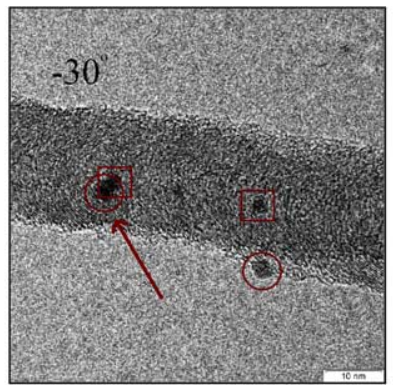

(c)

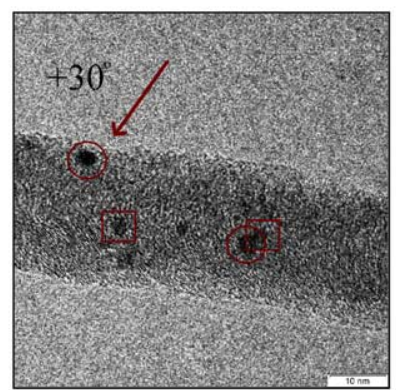

(g)

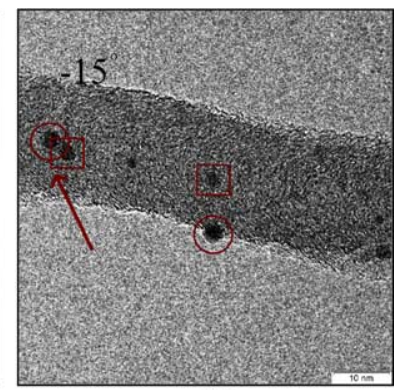

(d)

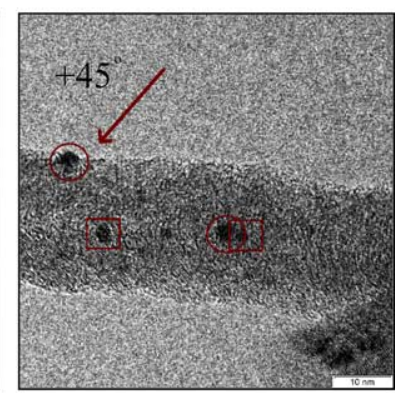

(h)

Fig. 5. TEM tilt series over an angular tilt range with palladium particles on the inside $(\square)$ as well as on the outside $(\bigcirc)$ of the fiber. The tilt axis was chosen parallel to the length of the fiber. Arrows show a particle that appears to have a hemispherical shape when observed from the side.

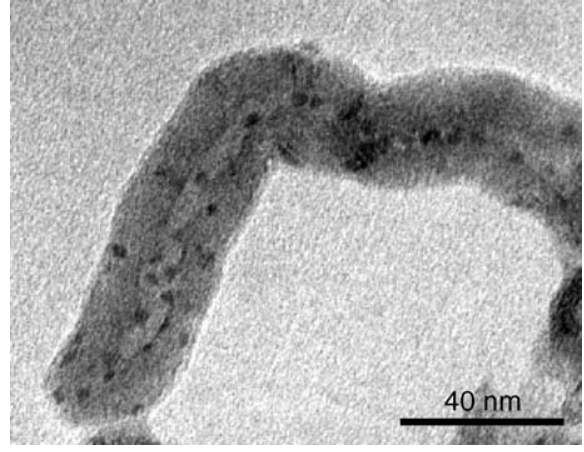

Fig. 6. TEM images of $\mathrm{Co} / \mathrm{CNF}$, both particles on the inside and outside are present.

range give more detailed information about the actual position of the metal particles in the catalyst. In Fig. 5 a series of TEM images of $\mathrm{Pd} / \mathrm{CNF}$ is depicted wherein the tilt axis, which was chosen parallel to the length of the fiber, is varied over a large angular range. In this series the displacement of four encircled Pd particles is key. When a metal particle is situated on the external surface of the fiber along with tilting the position of the particle should be largely determined by the tilt angle. In contrast to this, no or hardly any translation should occur upon tilting when a particle is situated inside the core of the fiber. From the sequence of images it can be concluded that the particles denoted with a circle appear to be on the external surface of the fiber. The particles denoted by a square are located inside the fiber. Clearly, Pd particles are present both on the inside of the core and on the external surface over the entire length of these fishbone fibers. Similar results were found with the $\mathrm{Co} / \mathrm{CNF}$ samples (Fig. 6).

The presence of $\mathrm{Pd}$ particles in the inner tubes strongly suggests that the required adsorption sites brought about by treatment in boiling $\mathrm{HNO}_{3}$ are also present on the internal surface and that this inner tube is accessible for the metal precursor solutions and later on for $\mathrm{H}_{2}$ to make reduction of the precursor possible. Also, with $\mathrm{Co} / \mathrm{CNF}$ we found that treatment of $\mathrm{CNF}$ with nitric acid is necessary to effectuate catalysts with high metal dispersions. Without this oxidative pre-treatment cobalt clusters as large as $300 \mathrm{~nm}$ were obtained on the surface of the macroscopic CNF bodies, while no cobalt particles on the internal surface of the fibers were found. Earlier studies on the deposition of $\mathrm{Ni}, \mathrm{Pt}$ and $\mathrm{Ru}$ on CNF showed that deposition of metals using similar preparation methods is only possible when the surface of the fibers is oxidized [40,41].

To get an impression of the distribution ratio of the metal phase between internal and external surface we localized over $720 \mathrm{Pd}$ particles distributed over 100 different fibers (Table 2). In the 2D TEM images about $28 \%$ of the Pd particles measured appears to overlap with the 2D-projection of the fiber core. By calculation we found that the percentage of external surface area of the fiber overlapping with the 2D-projection of the fiber core is about $13 \%$ of the total external surface area, with the assumption that the fibers have an average diameter of $35 \mathrm{~nm}$ with an inner average core of $7 \mathrm{~nm}$. Therefore, in case of a homogeneous distribution exclu- 
Table 2

Percentage of metal particles situated in the inner tube of the fibers for $\mathrm{Pd} / \mathrm{CNF}$ and $\mathrm{Co} / \mathrm{CNF}$ as determined with TEM and XPS

\begin{tabular}{lll}
\hline Sample & $\begin{array}{l}\% \text { Metal in inner tube } \\
\text { (TEM) }\end{array}$ & $\begin{array}{l}\% \text { Metal in inner tube } \\
\text { (XPS) }\end{array}$ \\
\hline $\mathrm{Pd} / \mathrm{CNF}$ & 15 & 10 \\
$\mathrm{Co} / \mathrm{CNF}$ & 34 & 28 \\
\hline
\end{tabular}

sively over the external surface of the fibers, the percentage of Pd overlapping the fiber core should be about $13 \%$, which is considerably lower than the percentage observed. These results give an indication of the percentage of $\mathrm{Pd}$ inside the fibers, i.e. $15 \%$. The ratio between the surface area of the inner tube and the total surface area is of about the same order $(17 \%)$ as the percentage of Pd on the internal surface. This indicates that the distribution over the fibers is rather homogeneous over the internal as well as the external surface and that the inner tubes are completely accessible for metal deposition using the ion adsorption method. Furthermore, no significant differences in metal particle size between particles situated on the internal or external surface were observed.

With the Co/CNF catalyst over 410 particles distributed on 80 fibers were examined. The mean Co particle size turned out to be $4 \mathrm{~nm}$, which corresponds nicely to the particle size found with XRD. Nearly $47 \%$ of the particles seemed to overlap in 2D-TEM micrographs with the inner tubes of the fibers, whereas a homogeneous coverage of internal and external surface should have given the value of $28 \%$, as argued above. This strongly indicates that about $34 \%$ of Co particles is present in the inner tubes of the fibers.

With XPS analysis metal particles located in the inner tubes of the fibers give no contribution in signal, due to the short mean free path of excitated electrons in graphite $(2.6 \mathrm{~nm})$ and the relatively large thickness of the fibers $(14 \mathrm{~nm})$. This loss in signal gives valuable information about the percentage of metal particles situated at the inner surface of the fibers (Table 2). In the calculation we assumed that the Pd particles in Pd/CNF have hemispherical shapes, which we inferred from TEM. The shape of the particles can be inferred from the TEM tilt series if a particle is situated on the edge of the fiber in the TEM micrograph as indicated by the arrows in Fig. 5. For $\mathrm{Co} / \mathrm{CNF}$, also in line with our TEM results, a spherical particle shape was used. The weight percentage of metal situated in the inner tubes of CNF was determined by calculating from the XPS data the metal loading at the averaged metal particle sizes (as determined with TEM). The calculated metal loading reflects the weight percentage of metal situated at the external surface of the fibers. With this information we calculated that according to XPS analysis, about $10 \%$ of the metal particles of $\mathrm{Pd} / \mathrm{CNF}$ and $28 \%$ of $\mathrm{Co} / \mathrm{CNF}$ appears to be at the internal surface, which is readily in line with the observations with TEM analysis.

The relative high percentage of Co inside the tubes prepared by wet impregnation compared to the nominal fraction of $\mathrm{Pd}$ present inside the $\mathrm{Pd} / \mathrm{CNF}$ catalyst prepared using ion adsorption points out that different loading processes result in different distributions. On basis of the increase in pore volume due to the treatment of the fibers in nitric acid we would expect $32 \%$ of metal to be present on the internal surface when applying the wet-impregnation method. When ion adsorption is used the surface ratio between inner and outer tube (17\%) should govern the fraction of metal particles located inside the fibers. Above values are close to the fractions of metal particles present in the inner tube of the samples.

\section{Conclusions}

We have demonstrated that treatment of fishbonetype $\mathrm{CNF}$ in nitric acid results in opening of the inner tubes $(4-9 \mathrm{~nm})$ of the fibers and the creation of anchoring sites for the metal precursors. Results show that, depending on the synthesis method, $28-34 \%$ of Co and $10-15 \%$ Pd end up in the inner cores of these fibers. It is demonstrated that tilting the axis during TEM analysis gives very valuable information about the location of metal particles in CNF supported catalysts. Location of the metal particles on the internal surface of the fibers can be disadvantageous from a catalytic perspective, because mass transfer limitations in the narrow tubes of the fibers may arise, especially in liquid phase processes.

\section{Acknowledgments}

H. Oosterbeek and P. Companje are kindly thanked for performing the XPS measurements and A.J.M. Mens for the $\mathrm{N}_{2}$ physisorption experiments. The authors want to acknowledge The Netherlands Technology Foundation (CW/STW 790.35.733) and Shell Research for financial support.

\section{References}

[1] de Jong KP, Geus JW. Carbon nanofibers: catalytic synthesis and applications. Catal Rev-Sci Eng 2000;42(4):481-510.

[2] Serp P, Corrias M, Kalck P. Carbon nanotubes and nanofibers in catalysis. Appl Catal A: Gen 2003;253(2):337-58.

[3] Hoogenraad MS. Growth and utilization of carbon fibrils. Ph.D. thesis, Utrecht University, The Netherlands, 1995.

[4] Tsang SC, Chen YK, Harris PJF, Green MLH. A simple chemical method of opening and filling carbon nanotubes. Nature 1994;372(6502):159-62.

[5] Tsang SC, Harris PJF, Green MLH. Thinning and opening of carbon nanotubes by oxidation using carbon dioxide. Nature 1993;362(6420):520-2. 
[6] Ajayan PM, Ebbesen TW, Ichihashi T, Iijima S, Tanigaki K, Hiura H. Opening carbon nanotubes with oxygen and implications for filling. Nature 1993;362(6420):522-5.

[7] Teunissen W. Tailoring of carbon fiber and carbon-coated ferromagnetic catalyst supports. Ph.D. thesis, Utrecht University, The Netherlands, 2000.

[8] Ros TG, van Dillen AJ, Geus JW, Koningsberger DC. Surface structure of untreated parallel and fishbone carbon nanofibres: an infrared study. Chem Phys Chem 2002;3(2):209-14.

[9] Ren WC, Cheng HM. Herringbone-type carbon nanofibers with a small diameter and large hollow core synthesized by the catalytic decomposition of methane. Carbon 2002;41(8):1657-60.

[10] Endo M, Kim YA, Hayashi T, Fukai Y, Oshida K, Terrones M, et al. Structural characterization of cup-stacked-type nanofibers with an entirely hollow core. Appl Phys Lett 2002; 80(7):1267-9.

[11] Otsuka K, Abe Y, Kanai N, Kobayashi Y, Takenaka S, Tanabe E. Synthesis of carbon nanotubes on $\mathrm{Ni} /$ carbon-fiber catalysts under mild conditions. Carbon 2004;42(4):727-36.

[12] Ajayan PM, Iijima S. Capillarity-induced filling of carbon nanotubes. Nature 1993;361(6410):333-4.

[13] Ajayan PM, Stephan O, Redlich P, Colliex C. Carbon nanotubes as removable templates for metal-oxide nanocomposites and nanostructures. Nature 1995;375(6532):564-7.

[14] Ajayan PM, Colliex C, Lambert JM, Bernier P, Barbedette L, Tence M, et al. Growth of manganese filled carbon nanofibers in the vapor phase. Phys Rev Lett 1994;72(11):1722-5.

[15] Lago RM, Tsang SC, Lu KL, Chen YK, Green MLH. Filling carbon nanotubes with small palladium metal crystallites: the effect of surface acid groups. J Chem Soc, Chem Commun 1995; 13:1355-6.

[16] Tessonier J-P, Pesant L, Pham-Huu C, Ehret G, Ledoux MJ. Carbon nanotubes: a highly selective support for the $\mathrm{C}=\mathrm{C}$ hydrogenation reaction. Stud Surf Sci Catal 2002;143:697-704.

[17] Pham-Huu C, Keller N, Ehret G, Charbonnierre LJ, Ziessel R, Ledoux MJ. Carbon nanofiber supported palladium catalyst for liquid-phase reactions. An active and selective catalyst for hydrogenation of cinnamaldehyde into hydrocinnamaldehyde. J Mol Catal A: Chem 2001;170(1-2):155-63.

[18] Pham-Huu C, Keller N, Charbonnierre LJ, Ziessel R, Ledoux MJ. Carbon nanofiber supported palladium catalyst for liquid-phase reactions. An active and selective catalyst for hydrogenation of $\mathrm{C}=\mathrm{C}$ bonds. Chem Commun 2000:1871-2.

[19] Park C, Keane MA. Catalyst support effects: gas-phase hydrogenation of phenol over palladium. J Colloids Interface Sci 2003;266(1):183-94.

[20] Hoogenraad MS, van Leeuwarden RAGMM, van Breda Vriesman GJB, Broersma A, van Dillen AJ, Geus JW. Metal catalysts supported on a novel carbon support. Stud Surf Sci Catal 1995;91:263-71.

[21] Hoogenraad MS, Onwezen MF, van Dillen AJ, Geus JW. Supported catalysts based on carbon fibrils. Stud Surf Sci Catal 1996;101:1331-9.

[22] Liu Z-J, Yuan Z-Y, Zhou W, Peng L-M, Xu Z. Co/carbonnanotube monometallic system: the effects of oxidation by nitric acid. Phys Chem Chem Phys 2001;3:2518-21.

[23] Chambers A, Nemes T, Rodriguez NM, Baker RTK. Catalytic behaviour of graphite nanofiber supported nickel particles Comparison with other supported media. J Phys Chem B 1998; 102(12):2251-8.
[24] Baker RTK, Laubernds K, Wootsch A, Paál Z. Pt/graphite nanofiber catalyst in $n$-hexane test reaction. J Catal 2000;193:165-7.

[25] Planeix JM, Coustel N, Coq B, Brotons V, Kumbhar PS, Dutartre $\mathrm{R}$, et al. Application of carbon nanotubes as supports in heterogeneous catalysis. J Am Chem Soc 1994;116:7935-6.

[26] Steigerwalt ES, Deluga GA, Cliffel DE, Lukehart CM. A Pt-Ru/ graphite carbon nanofiber nanocomposite exhibiting high relative performance as a direct-methanol fuel cell anode catalyst. J Phys Chem B 2001;105(34):8097-101.

[27] Rodriguez NM. A review of catalytically grown carbon nanofibers. J Mater Res 1993;8(12):3233-50.

[28] Toebes ML, Bitter JH, vanDillen AJ, de Jong KP. Impact of the structure and reactivity of nickel particles on the catalytic growth of carbon nanofibers. Catal Today 2002;76(1):33-42.

[29] Toebes ML, Prinsloo FF, Bitter JH, van Dillen AJ, de Jong KP. Influence of oxygen-containing surface groups on the activity and selectivity of carbon nanofiber-supported ruthenium catalysts in the hydrogenation of cinnamaldehyde. J Catal 2003;214(1):78-87.

[30] Winter F, van Dillen AJ, de Jong KP. Single-stage liquid-phase synthesis of methyl isobutyl ketone under mild conditions. J Mol Catal A Chem 2004;219(2):273-81.

[31] Bezemer GL, van Laak A, van Dillen AJ, de Jong KP. Cobalt supported on carbon nanofibers-a promising novel FischerTropsch catalyst. Stud Surf Sci Catal 2004;147:259-64.

[32] Gijzeman OLJ. XPS Analysis of Catalyst Surfaces. Utrecht University, Utrecht, The Netherlands, unpublished.

[33] Kuipers HPCE. Quantitative photoelectron spectroscopy as applied to non-ideal surfaces. Solid State Ionics 1985;16:15-22.

[34] Kuipers HPCE, van Leuven HCE, Visser WM. The characterization of heterogeneous catalysts by XPS based on geometrical probability. 1: Monometallic catalysts. Surf Interface Anal 1986;8(6):235-42.

[35] Nijkamp M. Hydrogen storage using physisorption. Modified carbon nanofibers and related materials. Ph.D. Thesis, Utrecht University, The Netherlands, 2002.

[36] Toebes ML, van Heeswijk JMP, Bitter JH, van Dillen AJ, de Jong KP. The influence of oxidation on the texture and the number of oxygen-containing surface groups of carbon nanofibers. Carbon 2004;42(2):307-15.

[37] Koster AJ, Ziese U, Verkleij AJ, Janssen AH, de Jong KP. Threedimensional transmission electron microscopy: a novel imaging and characterization technique with nanometer scale resolution for materials science. J Phys Chem B 2000;104(40):9368-70.

[38] Janssen AH, van der Voort P, Koster AJ, de Jong KP. A 3DTEM study of the shape of mesopores in SBA-15 and modified SBA-15 materials. Chem Commun 2002;15:1632-3.

[39] Janssen AH, van der Voort P, Koster AJ, de Jong KP. Threedimensional transmission electron microscopic observations of mesopores in dealuminated zeolite Y. Angew Chem Int Ed 2002;40(6):1102-4.

[40] Bitter JH, van der Lee MK, Slotboom AGT, van Dillen AJ, de Jong KP. Synthesis of highly loaded highly dispersed nickel on carbon nanofibers by homogeneous deposition-precipitation. Catal Lett 2003;89(1-2):139-42.

[41] Toebes ML, van der Lee MK, Tang LM, Huis in 't Veld MH, Bitter JH, van Dillen AJ, et al. Preparation of carbon nanofiber supported platinum and ruthenium catalysts: comparison of ion adsorption and homogeneous deposition precipitation. J Phys Chem B 2004;108:11611-9. 